\title{
Study of oral health among adolescents in the field practice area of Urban health training centre, Nanded, India
}

\author{
Inamdar I.F. ${ }^{1}$, Mohammed Ubaidulla ${ }^{2}$, Saleem H. Tambe ${ }^{3}$, Doibale M.K ${ }^{4}$. \\ Aswar N.R. ${ }^{5}$ \\ 1-Assistant Professor - Department of Community Medicine \\ 2-Assistant Professor-Department of General Medicine \\ 3- Assistant Professor- Department of Pediatrics \\ 4- Professor \& Head-Department of Community Medicine \\ 5- Associate Professor-Department of Community Medicine \\ Dr. S.C. Government Medical College, Nanded, Maharashtra, India
}

\begin{abstract}
:
Background: Oral health is essential to quality of life as it ensures social and physical well-being and it acts as the mirror which reflects general health. Oral diseases are topping the list of some common diseases in the world. Poor oral hygiene is a known important predisposing factor of some oral diseases like cancrum oris, periodontitis, acute necrotizing ulcerative gingivitis etc. Research question: What is the oral health status among adolescents age group? Aim \& objectives: To find out factors affecting oral health status among adolescents. Study design: Cross-sectional study in urban slum areas, house to house survey was carried out to study epidemiological profile of oral health among adolescents. Oral cavity examination of study population was done with the help of torch or natural light. Setting: Field practice area of urban health training centre, Shivaji Nagar, Nanded. Participants: - 718 Study subjects from urban health centre field practice area. Results: - Prevalence of dental caries was found 33\% among adolescents and $27 \%$ adolescents were having more than one oral morbidity. The other dental conditions like plaque, tartar, oral ulcer, candidacies, bleeding gums, injuries, calculus and fibrosis were also seen among adolescents. Statistically significant difference was noted with dental caries and type of cleaning aids $\left(\chi^{2}=18.39\right.$ d.f. $\left.=2 p<0.001\right)$, cleaning material aids and prevalence of dental caries $\left(\chi^{2}=30.69\right.$ d.f. $\left.=4 p<0.01\right)$, Frequency of tooth cleaning and dental caries $\left(\chi^{2}=6.07\right.$ d.f. $=1$ $p<0.05)$, Rinsing of mouth after meals and prevalence of dental caries $\left(\chi^{2}=9.06 \mathrm{~d} . f .=2 p<0.05\right)$ Conclusion: Oral health (diseases) strongly related with frequency of mouth washing, type of cleaning aids, rinsing of mouth. There is need for accessible and affordable oral health services. Awareness among adolescents about oral health should be encouraged.
\end{abstract}

Key-Words: - Oral health, adolescents, teeth decay, addiction and literacy status.

\section{Introduction}

Oral health means more than just healthy teeth. Oral health affects people physically and psychologically and influences how they grow, look, speak, chew, taste food and socialize, as well as their feelings of social wellbeing. It is essential to the quality of life as it ensures social and physical well-being. ${ }^{(1)}$ Oral health is fundamental to overall health and quality of life. ${ }^{(2)}$ A healthy mouth enables people to eat, speak and socialize without pain, discomfort or embarrassment. ${ }^{(3)}$

General health and oral health are inseparable, oral cavity is the mirror which reflects general health. Oral diseases are topping the list of some common diseases in the world. The chronic, recurrent, irreversible cumulative and prevalent nature of oral diseases has contributed to wrong belief that oral problems are inevitable and not preventable.

In India, the prevalence of dental caries is $80 \%$ with 5 decayed teeth per child on an average at the age of 16 years. In some populations, the prevalence rate of periodontal diseases approach $90-100 \%$. It is a fact that oral hygiene is seen as a natural part of total body cleanliness and that people desire fresh and healthy mouth with good smelling breath. ${ }^{(4-6)}$. Oral health includes having healthy teeth and gums, but it also means that people's lives are not affected by a range of other conditions including diseases of the oral mucosa, cancers of the mouth and throat, problems, or trauma to the jaw or middle of the face. ${ }^{(7-10)}$

Poor oral hygiene is a known important predisposing factor of some oral diseases like cancrum oris, periodontitis, acute necrotizing ulcerative gingivitis (ANUG) and gingivitis. ${ }^{(1)}$ Oral hygiene and personal hygiene are the cheapest form of preventive health measure. Though cheap, it is surprisingly one of the most ignored in practice especially in the underprivileged rural and urban slum communities. ${ }^{12)}$ Higher caries 
prevalence is anticipated in adolescent age group who may also not understand and assume responsibility for or co-operate with preventive oral health practices. ${ }^{(13)}$

Globally, poor oral health among rural and slum population is due to high possibility of tooth loss, dental caries experience and the prevalence rates of periodontal disease, xerostomia and oral pre-cancer / cancer. The negative impact of poor oral conditions on the quality in rural and slum settings is an important public health issue. In developing countries the challenges to provision of primary oral health care are particularly high because of shortage of dental manpower. ${ }^{(14)}$ Considering these facts in mind the present study was carried out to determine the oral health status of adolescents from field practice area of urban health training centre, Nanded.

\section{Objectives}

To study the oral health status and various factors affecting on oral health status among adolescents.

\section{Material \& Methods}

Present community based cross sectional study was carried out at field practice area of urban health training centre, Shivaji nagar, Nanded. There are eight slum areas attached to urban health training centre.

3.1) Sample size: $-25 \%$ of slums covered by urban health training centre were selected by simple random technique, which comes out to two slum area named Navi Aabadi and Jaibhim Nagar.

3.2) Place of study: - field practice area of urban health centre.

3.3) Study period: - August 2011 to February 2012

3.4) Study population: - Total adolescents population was 782 in two selected slum areas, of which 64 adolescents excluded due to reasons like non availability during survey, acute illness, nonparticipation, locked houses, migration etc. Hence 718 adolescents formed the study subjects.

3.5) Data collection: - House to house survey was conducted by a team consisting of authors, with the help of dentist and female social workers. A pre tested, pre designed questionnaire was used to collect the information. Consent was obtained after explaining the purpose the study and taking in confidence from participants and their parents. Adolescent age group ranging from 10 to 19 yrs. of age ${ }^{(15)}$ included in the study. Only clinical oral examination of all the subjects was done with the help of torch and bright sun light.

3.6) Instruments used for examination: -Plain mouth mirror, periodontal probes, two containers (one for used instruments and one for sterilized instruments), concentrated sterilizing solution, soap and water. With proper use of mouth mirror and periodontal probe all areas of oral cavity could be fully examined without the need for digital manipulation of the oral tissues hence reducing the risk of cross infection.

3.7) Terminologies used: -

3.7.1) Mishri: Burnt form of powdered tobacco.

3.7.2) Manjan: crushed coal powder.

3.7.3) Datun: Small stem of miswaq plant /neem tree

3.7.4) Dentition status: For assessment of dental caries - a microbial disease of the calcified tissues of teeth, characterized by demineralization of the inorganic portion and destruction of the organic substance of the tooth.

3.8) Statistical tests: - percentages, chi-square test

\section{Results}

Present community based cross sectional study was carried out to study the oral health status and factors affecting oral health among adolescents in slums of field practice area of Nanded city which included 437 boys and 281 girls. For the purpose of statistical analysis the adolescents were grouped into two groups of less than fifteen years and above fifteen years of age.

Table No. 1. Socio demographic characteristics of the study subjects.

\begin{tabular}{|l|l|l|l|}
\hline 1 & Age and sex wise distribution of study subjects & $>15$ years \\
\hline & Sex & $<15$ years & $259(36.07 \%)$ \\
\hline & Boys $\{\mathrm{n}=437(60.86 \%)\}$ & $178(24.79 \%)$ & $173(24.09 \%)$ \\
\hline & Girls $\{\mathrm{n}=281(39.14 \%)\}$ & $108(15.04 \%)$ & $432(60.16 \%)$ \\
\hline & Total $\{\mathrm{n}=718(100 \%)\}$ & $286(39.83 \%)$ & $\%$ \\
\hline 2 & Religion wise distribution of study subjects & No. & 19.22 \\
\hline & Religion & 138 & 36.35 \\
\hline & Hindu & 261 & 38.16 \\
\hline & Muslim & 274 & 06.27 \\
\hline & Buddhist & 45 & 100 \\
\hline & Others & 718 & $\%$ \\
\hline & Total & \multicolumn{2}{l}{} \\
\hline 3 & Distribution of study subjects according to Socioeconomic class \\
\hline & Class & No. & \\
\hline
\end{tabular}




\begin{tabular}{|l|l|l|l|}
\hline & Class I & 11 & 1.53 \\
\hline & Class II & 58 & 8.08 \\
\hline & Class III & 124 & 17.27 \\
\hline & Class IV & 227 & 31.62 \\
\hline & Class V & 298 & 41.50 \\
\hline & Total & 718 & 100 \\
\hline 4 & Distribution of study subjects according to type of family & $\%$ \\
\hline & Family type & No. & 18.25 \\
\hline & Nuclear & 131 & 46.23 \\
\hline & Joint & 332 & 35.52 \\
\hline & Three Generation & 255 & 100 \\
\hline & Total & 718 & $\%$ \\
\hline 5 & Distribution of study subjects according to literacy status & 22.01 \\
\hline & Education & Number. & 45.82 \\
\hline & Illiterate & 158 & 32.17 \\
\hline & Primary & 329 & 100 \\
\hline & Sec.\& above & 231 & 718 \\
\hline & Total & \multicolumn{2}{|l}{} \\
\hline
\end{tabular}

Table no. 1 shows study of some socio-demographic characteristics of the study subjects including sex and age wise distribution in which $178(24.79 \%)$ were male of less than 15 years age group while $259(36.07 \%)$ were above 15 years of age group. $108(15.04 \%)$ and $173(24.09 \%)$ were female of less than 15 years and above 15 years of age group respectively. Highest number of adolescents were from Buddhist and Muslim i.e. 38.16\% and $36.35 \%$ respectively while $6.27 \%$ were from other religion like Jain, Christian etc. Majority of the adolescent's family belong to class V (41.50\%) and Class IV (31.62\%) of the socioeconomic class by B.G. Prasad's modified classification ${ }^{(15)}$. Highest number of the adolescents was from joint family $(46.23 \%)$ and three generation family $(35.52 \%)$. A total $158(22.01 \%)$ adolescent were illiterate while $329(45.82 \%)$ and 231 $(32.17 \%)$ were primary and secondary school pass.

Table 2. Oral health status of the study subjects:

\begin{tabular}{|l|l|l|l|}
\hline Oral morbidity & Male (\%) & Female (\%) & Total (\%) \\
\hline Nil & $287(39.97)$ & $194(20.02)$ & $481(66.99)$ \\
\hline Dental caries & $129(17.96)$ & $108(15.04)$ & $237(33)$ \\
\hline plaque & $42(5.84)$ & $54(7.52)$ & $96(13.37)$ \\
\hline Tartar & $30(4.17)$ & $18(2.50)$ & $48(6.68)$ \\
\hline Oral candidacies & $04(0.55)$ & $01(0.13)$ & $05(0.68)$ \\
\hline Ulcer & $27(3.76)$ & $14(1.94)$ & $41(5.71)$ \\
\hline Fibrosis & $02(0.27)$ & 00 & $02(0.27)$ \\
\hline Injuries & $37(5.15)$ & $22(3.06)$ & $59(8.21)$ \\
\hline Bleeding gums & $32(4.45)$ & $41(5.71)$ & $73(10.16)$ \\
\hline Calculus & $19(2.64)$ & $14(1.94)$ & $33(4.59)$ \\
\hline Dental fluorosis & $06(0.83)$ & $03(0.41)$ & $09(1.25)$ \\
\hline Other & $04(0.55)$ & $02(0.27)$ & $06(0.82)$ \\
\hline
\end{tabular}

Table number 2 shows the oral health status of the study subjects. Out of 718 adolescents, around $67 \%$ (481) adolescents were having normal oral hygiene, while $33 \%$ (237) were having dental caries and $27 \%$ adolescents were having more than one oral morbidity. The other dental conditions like plaque, tartar, oral ulcer, candidacies, bleeding gums, injuries, calculus, fibrosis, fluorosis, etc were also noted. Maximum oral health and dental problems were seen among male as compare to the female adolescents.

Table 3: Association of various indicators with dental caries among study subjects

\begin{tabular}{|c|c|c|c|c|}
\hline \multirow[t]{2}{*}{ Indicators } & \multicolumn{2}{|c|}{ Dental caries } & \multirow{2}{*}{ Total } & \multirow[b]{2}{*}{$P$ value } \\
\hline & Present & Absent & & \\
\hline \multicolumn{5}{|c|}{ Type of cleaning aids } \\
\hline Finger & $137(40.89 \%)$ & $198(59.11 \%)$ & $335(46.66 \%)$ & \multirow{4}{*}{$\begin{array}{l}\chi^{2}=18.39 \quad \text { d.f. }= \\
2 \\
p<0.001\end{array}$} \\
\hline Tooth-brush & $71(24.91 \%)$ & $214(75.09 \%)$ & $285(39.69 \%)$ & \\
\hline Datun & $29(29.59 \%)$ & $69(70.41 \%)$ & $98(13.65 \%)$ & \\
\hline Total & $237(33 \%)$ & $481(67 \%)$ & $718(100 \%)$ & \\
\hline \multicolumn{5}{|c|}{ Cleaning material aids } \\
\hline Tooth paste & $60(28.17 \%)$ & $153(71.83 \%)$ & $213(29.66 \%)$ & \multirow[b]{3}{*}{$\chi^{2}=30.69$} \\
\hline Tooth powder & $71(26.39 \%)$ & $198(73.60 \%)$ & $269(37.46 \%)$ & \\
\hline Mishri & $39(44.31 \%)$ & $49(55.69 \%)$ & $88(12.26 \%)$ & \\
\hline
\end{tabular}


Study of oral health among adolescents in the field practice area of Urban health training centre,

\begin{tabular}{|c|c|c|c|c|c|}
\hline Manjan & $53(41.08 \%)$ & $76(59.92 \%)$ & $129(17.96 \%)$ & \multirow{3}{*}{\multicolumn{2}{|c|}{$\begin{array}{l}\text { d.f. }=4 \\
\text { p }<0.01\end{array}$}} \\
\hline Nil & $14(73.69 \%)$ & $05(26.31 \%)$ & $19(2.65 \%)$ & & \\
\hline Total & $237(33 \%)$ & $481(67 \%)$ & $718(100 \%)$ & & \\
\hline \multicolumn{6}{|c|}{ Frequency of tooth cleaning } \\
\hline Once & $221(34.74 \%)$ & $415(65.26 \%)$ & $636(88.58 \%)$ & \multirow{3}{*}{\multicolumn{2}{|c|}{$\begin{array}{l}\chi^{2}=6.07 \\
\text { d.f. }=1 \\
\text { p }<0.05\end{array}$}} \\
\hline Twice or more & $16(19.51 \%)$ & $66(80.49 \%)$ & $82(11.42 \%)$ & & \\
\hline Total & $237(33 \%)$ & $481(67 \%)$ & $718(100 \%)$ & & \\
\hline \multicolumn{6}{|c|}{ Rinsing of mouth after meals } \\
\hline Once & $35(28 \%)$ & $90(72 \%)$ & $125(17.41 \%)$ & \multirow{4}{*}{$\begin{array}{l}\chi^{2}=9.06 \\
\text { d.f. }=2\end{array}$} & \multirow{4}{*}{$\mathrm{p}<0.05$} \\
\hline Twice or more & $13(19.40 \%)$ & $54(80.60 \%)$ & $67(9.33 \%)$ & & \\
\hline Nil & $189(35.93 \%)$ & $337(64.07 \%)$ & $526(73.26 \%)$ & & \\
\hline Total & $237(33 \%)$ & $481(67 \%)$ & $718(100 \%)$ & & \\
\hline
\end{tabular}

Table no. 3 shows association of various indicators with dental caries among adolescents. Around $47 \%$ (335) study subjects used finger as cleaning aid, of which $41 \%$ (137) had dental caries compared to $24.91 \%$ of those used tooth brush and $29.59 \%$ who used Datun as cleaning aid. This difference was found statistically significant $\left(\chi^{2}=18.39\right.$ d.f. $\left.=2 \mathrm{p}<0.05\right)$. The cleaning materials used for cleaning of teeth were tooth paste, tooth powder, manjan, mishri etc. Total $12.26 \%$ adolescents were using Mishri, $17.96 \%$ were using Manjan while $37.46 \%$ and $29.66 \%$ were using tooth powders and tooth paste respectively. Maximum number of dental caries was found among adolescents not using any cleaning material $(73.69 \%)$ and manjan and mishri users. The statistically significant difference was found with use of different cleaning material and dental caries $\left(\chi^{2}=30.69\right.$ d.f. $=4 \mathrm{p}<0.001)$. Majority of the study subjects $(88.58 \%)$ were cleaning their teeth once in the day while $11.42 \%$ were twice or more per day. Those who were having more frequency of cleaning teeth had less prevalence of caries. The difference was statistically significant $\left(\chi^{2}=6.07\right.$ d.f. $\left.=1 \mathrm{p}<0.05\right)$. Only 192 study subjects who practiced rinsing of their mouth after consumption of food. $35.93 \%$ study subjects had dental caries who did not rinse their mouth after food consumption. When chi square test was applied for presence of dental caries and frequency of rinsing the mouth after meals, it was found statistically significant $\left(\chi^{2}=9.06\right.$ d.f. $=2 \mathrm{p}<0.05)$.

Table 4. Association between tobacco use and Dental caries.

\begin{tabular}{|l|l|l|l|}
\hline \multirow{2}{*}{ Dental caries } & \multicolumn{2}{|l|}{ Tobacco consumption } & Total \\
\cline { 2 - 3 } & Yes & No & \\
\hline Present & 51 & 186 & 237 \\
\hline Absent & 62 & 419 & 481 \\
\hline Total & 113 & 605 & 718 \\
\hline
\end{tabular}

Table number 4 shows association between tobacco use and dental caries. Out of 718 adolescents, 113 were using either smoke or smokeless form of tobacco. The addiction of tobacco was labeled when the users having habit since last six months. The statistically significant difference was found $\left(\chi^{2}=8.92 \mathrm{df}=1 \mathrm{p}<0.1\right)$ among adolescents having habit of tobacco use with dental caries.

\section{Discussion}

Oral diseases have a significant impact on the health and well being of the nation through pain, morbidity and mortality and through lost capacity to undertake school, social and economic activities. The oral diseases, dental caries, are the most common diseases of all the ages. In the present community based study, prevalence of dental caries among adolescent was $33 \%$ which is very high. Bhowate R.R. et al ${ }^{(5)}$ reported $^{(6)}$ prevalence rate of dental caries as 53.5\% for 11-15 years age group and Goyal R.C. et al ${ }^{(6)}$ showed prevalence of dental caries as $53.18 \%$ which is higher than present study. This high prevalence of poor oral health against the background of low socioeconomic conditions in these adolescents, as more than $41 \%$ of study population was below poverty line. In the present study most of the adolescents $(22 \%)$ interviewed had no formal education and around $46 \%$ with primary education. Richard and Barmes ${ }^{(16)}$ had shown that socioeconomic and educational levels of populations are directly related to the oral cleanliness and inversely related to the prevalence and severity of gingivitis and periodontitis. Many other studies have attributed the high prevalence of oral disease and the low level of oral health awareness to ignorance, poverty and lack of education. ${ }^{(17,18)}$

In the present study more than $46 \%$ of the subjects used finger as cleaning aid of which $40 \%$ had dental caries compared to only $24 \%$ of those who used tooth brush. Bhowate R.R et al ${ }^{(5)}$ reported from his study that $26.31 \%$ of subjects used toothbrush, which is similar to present study. Chakraborty $\mathrm{M}$ et al ${ }^{(19)}$ showed maximum prevalence of dental caries $(72.38 \%)$ among those who used fingers for cleaning their teeth followed by datun users $(67.5 \%)$. Goyal R.C. et $\mathrm{al}^{(6)}$ reported that dental caries was less $(46.63 \%)$ with brushing of teeth than other methods of cleaning $(53.37 \%)$. Somewhat similar results were also seen in other studies from Zambia. ${ }^{(20)}$ Out of 
192 subjects who practiced rinsing of their mouth after consumption of food 48 subjects had dental caries in contrast to 189 out of 526 subjects who did not practice rinsing after consumption of food. Chakraborty $\mathrm{M}$ et $\mathrm{al}^{(19)}$ also reported the similar results. Out of 718 adolescents, 113 were using either smoke or smokeless form of tobacco. The addiction of tobacco was labeled when the users having habit since last six months. Oral use of smokeless tobacco shows positive contributing factor for a higher incidence of dental caries predominantly tobacco chewing. One of the main reasons for the association between smokeless tobacco and dental caries is the presence of high amount of various sugars and sweeteners added during the commercial manufacturing of smokeless tobacco products ${ }^{(21)}$ Individuals who chew tobacco appear to have more dental caries than non-users. Review of studies conducted from 1988-90 on oral consequences chewing tobacco use showed a significantly higher prevalence of root caries than did comparable sites in non-smokers ${ }^{(22)}$

\section{Conclusions}

Oral health (diseases) strongly related with frequency of mouth washing, type of cleaning aids, rinsing of mouth. There is need for accessible and affordable oral health services. Awareness among adolescents about oral health should be encouraged. It is an emphasis that is directed to all health management disciplines of which oral health is an essential part. It imposes a challenge of developing culturally acceptable and sensitive programme that has the potential to provide knowledge and develop a health attitude in the population concerning oral health or by way of integrating scientific knowledge into traditional oral health beliefs.

\section{References}

[1] Charlotte Fatty Ndiaye Oral Health :A key to general health and well-being African Health Monitor January-June 2008

[2] Brennan DS, Spencer AJ (2004) Oral health trends among adult public dental patients. AIHW cat. no.DEN 127. Canberra : AIHW (Dental Statistics and Reasearch Series No. 30). Australia's National Health plan 2004-2013.

[3] Britt H, Sayer GP, Miller GC, Charles J, Scahill S, Horn F, Bhasale A, McGeechan K(1999) General Practice activity in Australia 1998-1999. Canberra: Australian Institute of Health and Welfare.

[4] Jayashree D. Chatufale, R.C. Goyal A Cross-Sectional Study of Factors Related to Oral Health in Rural Area of Loni, Western Maharashtra Indian journal of Community Medicine Vol. 27, No.2 (2002-04-2002-06)

[5] Bhowate RR, Borle SR. Dental health amongst 11-15 year old children in Sewagram, Maharashtra. Indian Journal of Dental Research. Apr-June 1994:5-6.

[6] Goyal Rc, Sachdeva NL, Somsundaram Kv. Oral Health Status of rural community in Western Maharashtra. Indian Journal of PSM. July-Dec1994;25(3):138-45.

[7] Chalmers JM (1999) Oral diseases in older adults In: Chalmers JM Ageing and Dental Health. AIHW Dental Statistics and Research Series No.19. Adelaide: The University of Adelaide.

[8] Chalmers JM(2003) Oral health promotion for our ageing Australian population. Australian Dental Journal $48(1)$ : 2-9.

[9] Halmers JM, Hodge CP, Fuss JM, Spencer AJ, Carter KD (2000) The Adelaide Dental Study of Nursing Homes 1998 AIHW cat. No. DEN 83. Adelaide: AIHW Dental Statistics and Research Unit (Dental Statistics and Research Series No.22).

[10] Chalmers JM, Hodge CP, Fuss JM, Spencer AJ, Carter KD (2001) The Adelaide Dental Study of Nursing Homes One-Year followup-1999. AIHW cat. No. DEN 84 Adelaide: AIHW Dental Statistics and Research Unit (Dental Statistics and Research Series No.23).

[11] Enwonwu CO, Falker WA. Idigbe. Orofacial gangrene (NOMA/Cancrum Oris) Pathogenic mechanisms. Crit Rev Oral Biol Med. 2000; 11(2):159-171.[PubMed].

[12] SN Okolo, GA Chukwu, I Egbuonu,FA Ezeogu, C Onwuanaku, OA Adeleke, A Hassan, and A Ngoe-Nesoah Oral Hygiene and Nutritional Status of Children Aged 1-7 Years in a Rural Community, Ghana Med J. 2006 March; 40(1): 22-25.

[13] Murray CJL, Lopez AD; Global burden of disease study. Lancet 1997. Pub med abstract.

[14] Management of Dental Caries in selected rural areas of Gujarat through Atraumatic Restorative Technique (ART) Report GoI WHO Collaborative Program (2006-07) Government Dental College and Hospital, Ahmedabad - 380 016, India)

[15] A.P. kulkarni and J.P. baride. Special care of adolescents. Text book of community medicine. Vora Publication, $2^{\text {nd }}$ edition, Page no 558 .

[16] Richards ND, Barmes DE. Social factors in dental epidemiology. In: Richards ND, Cohen LK, editors. Social Sciences and dentistry. Vol. 1. London: Quintessence; p. 318.

[17] Enwonwu CO, Falker, Idigbe EO, Savage KO. Noma (Cancrum Oris): Questions and answers. Oral Dis. 1999;5:144-149. [PubMed]

[18] Otuyemi OD, Abidoye RO, Dada D. Oral health knowledge, attitude and behaviour of 12 year-old sub-urban and rural school children in Nigeria. Afri Dent J. 1994;8:20-25.

[19] Chakraborti M, Saha JB, Bhattacharya RN. Epidemiological correlates of dental caries in an urban slum of West Bengal. Indian Journal of Public Health. 1997; XXXXI: 56-67

[20] Noar J, Portuoy S. Dental status of children in a primary and secondary school in rural Zambia. Int Dent J. 1991;41:142-148. [PubMed]

[21] Sajith Vellappally, Zdenek Fiala, Jindra Smejkalova, Vimal Jacob, Pilathadka Shriharsha Influence of tobacco use in dental caries development, Cent Eur J Public Health 2007; 15 (3): 116-121

[22] Robertson PB, Walsh MM, Greene JC. Oral effects of smokeless tobacco use by professional baseball players. Adv Dent Res. 1997 Sep;11(3):307- 12 . 